\title{
Evaluation of C-reactive protein as a biochemical marker for assessing disease severity in Malaria
}

\author{
Vandana Agrawal $^{1}$, Vaishali Jain ${ }^{2}$, Shubho Biswas ${ }^{2}$ \\ ${ }^{1}$ (Department of Pathology, L.N. Medical College and Research Centre,Bhopal,India) \\ ${ }_{2}^{2}$ (Department of Biochemistry, L.N. Medical College and Research Centre,Bhopal,India)
}

\begin{abstract}
Levels of C-reactive protein, a well characterised serum acute phase protein were measured in a total of 32 patients admitted to JK hospital with the diagnosis of Malaria (18 vivax malaria and 14 falciparum malaria) . Serum C-reactive protein concentrations were measured daily in all the patients over a seven day period .Percentage parasitemia, platelet count, serum bilirubin, alanine aminotransferase and aspartate aminotransferase levels were measured initially on the day of admission. Though Serum C-reactive protein concentration was significantly elevated in all the malaria patients, it was significantly higher $(P<0.01)$ in Plasmodium falciparum $(29.4 \pm 10.9 \mathrm{mg} / \mathrm{L}$ ) as compared to $P$. Vivax malaria $(14.5 \pm 3.7 \mathrm{mg} / \mathrm{L})$. The highest concentration was observed on day 2 ( Plasmodium falciparum :65.3 $\pm 16.8 \mathrm{mg} / \mathrm{L}$; Plasmodium vivax: $27.1 \pm 13.0 \mathrm{mg} / \mathrm{L}$ )and fell significantly between day 1 and day 7 in parallel with clinical recovery. A significant positive correlation was found between serum CRP and conventional laboratory markers of severity of malaria like percentage parasitemia, serum bilirubin, serum concentrations of alanine aminotransferase and aspartate aminotransferase in Plasmodium falciparum patients but not in Plasmodium Vivax.These results suggest that C-reactive protein can be used as a biomarker for assessing disease severity particularly in Plasmodium falciparum malaria.
\end{abstract}

Key words : Biochemical marker, C-reactive protein, malaria

Submitted date 20 June 2013

Accepted Date: 25 June 2013

\section{Introduction}

Malaria is a major public health problem in South East Asia [1] . Caused by Plasmodium parasite and transmitted through the bite of an infected female Anopheles mosquito, malaria still remains to be a major health burden particularly to the developing nations[2].

Several methods have been used to assess objectively the severity of Malaria . Clinical assessment of severity depends on bed side observation of variables such as blood pressure, fever and mental alertness. Laboratory markers include \% parasitemia, platelet count, serum sodium, serum albumin, serum bilirubin and urea concentrations [3]. But these tests are not always sensitive in estimating disease severity.

Recently some acute phase reactants have emerged as biomarkers in malaria infection in addition to chemokines and cytokines . In particular C-reactive protein(CRP) and nitric oxide (NO) have been identified as important inflammatory biomarkers [4,5].

CRP is an acute phase protein that is involved in the activation of complement, acceleration of phagocytosis and detoxification of substances released from the damaged tissue . Measurement of serum CRP is most frequently used for the evaluation of injury in the body tissue or for the detection of inflammatory event somewhere in the body . In malaria CRP secretion is induced by pro - inflammatory cytokines that are secreted by host mononuclear cells and strong correlations have been found between CRP levels and parasitemia [6]. In fact CRP levels have proven to be valuable in assessing the severity of malaria and as a prognostic tool in the follow up response to treatment [3].

As malaria is highly endemic in certain parts of India and since studies involving sequential measurement of CRP in malaria patients are quite few in India, this study was designed to evaluate whether serial measurements of CRP in malaria patients can be used to assess disease severity along with other haematological and biochemical parameters.

\section{Material And Methods}

The study was undertaken from May '2012 to March '2013. The study population consisted of 40 untreated malaria patients attending the Out-patient - department at LN Medical College and JK Hospital , Bhopal with symptoms of fever, rigor, headache and vomiting. Patients who tested positive for malaria by slide microscopy were enrolled in the study. All the patients were admitted to the hospital for treatment. Of the 40 , initially enrolled patients only 32 patients completed the study . 8 patients were lost to follow up. The 
patients included were between the age group of $12-55$ years of both the sexes. In all the patients malaria was the only diagnosis.

A finger prick blood sample was taken to prepare thick and thin blood films and stained with geimsa stain to determine the presence of malaria parasites. The following lab investigations were performed on first day of admission : percentage parasite count, platelet count, serum bilirubin, alanine aminotransferase (ALT) and aspartate aminotransferase (AST) .CRP was measured on daily serum samples for 7 days using high sensitivity immunoturbidimetric method ( Biosystems A25) with normal value $<5 \mathrm{mg} / \mathrm{l}$.

Written informed consent was obtained from all adult patients or from the parents of minor patients . The study was approved by the institutional ethics committee.

Statistical software used was SPSS (version 16). The patients were grouped according to the plasmodial species. :Plasmodium vivax $(\mathrm{n}=18)$ and Plasmodium falciparum $(\mathrm{n}=14)$. Comparison of means was carried out using student's $t$ test. Correlation between different variables was analysed by Pearson's correlation coefficient.

\section{Results}

Thirty two patients, both males and females were included in this study. Of them, 18 were Plasmodium vivax (Pv) and 14 were Plasmodium falciparum infected (Pf) [Table 1]. There was no case of mixed infection in our study. Fever with tremor was the commonest presenting symptom in both the cases. There was only 1 mortality due to Pf and none for Pv.

Table 2 shows the comparison of means of the various baseline laboratory investigations in $\mathrm{Pv}$ and $\mathrm{Pf}$ infected patients on the day of admission. Mean CRP concentration was significantly high in both Pf ( $29.4 \pm 10.9 \mathrm{mg} / \mathrm{L})$ and $\mathrm{Pv}(14.5 \pm 3.7 \mathrm{mg} / \mathrm{L})$ patients $(\mathrm{P}<0.01)$. The serum bilirubin concentration and platelet count was statistically different between the two groups.

In this study, CRP was measured on daily serum samples for 7 days . The highest concentration was observed on day 2 (Pf :65.3 $\pm 16.8 \mathrm{mg} / \mathrm{L} ; \mathrm{Pv}: 27.1 \pm 13.0 \mathrm{mg} / \mathrm{L}$ ). The CRP fell significantly between day 1 (Pf : $30.3 \pm 9.3 \mathrm{mg} / \mathrm{L} ; \mathrm{Pv}: 14.0 \pm 7.1 \mathrm{mg} / \mathrm{L}$ ) and day 7 ( Pf : $5.6 \pm 0.5 \mathrm{mg} / \mathrm{L} ; \mathrm{Pv}: 5.2 \pm 0.9 \mathrm{mg} / \mathrm{L}$ ) in parallel with clinical recovery except in the 1 case of P.falciparum where the patient succumbed to the disease. [Figure 1].

Correlation was sought between serum concentrations of CRP and various haematological and biochemical parameters, both in P.vivax and P.falciparum patients . A significant positive correlation was found between percentage parasitemia and serum CRP concentration in P.falciparum but not in P.Vivax. A significant positive correlation in P.falciparum infection was also found between CRP concentration, Serum bilirubin and serum concentrations of AST and ALT . Though platelet count was inversely correlated with CRP and percentage parasitemia in P.falciparum infection, this was not statistically significant [Table 3].

Table 1

Demographic and clinical profile of the studied population

\begin{tabular}{|l|c|c|}
\hline Variables & $\begin{array}{c}\text { Plasmodium vivax } \\
(\mathbf{n = 1 8})\end{array}$ & $\begin{array}{c}\text { Plasmodium falciparum } \\
(\mathbf{n = 1 4})\end{array}$ \\
\hline Male & 6 & 8 \\
\hline Female & 12 & 6 \\
\hline Clinical symptoms : & 18 & 14 \\
\hline Fever & 14 & 12 \\
\hline Tremor & 08 & 10 \\
\hline Headache & 05 & 08 \\
\hline Vomiting & 04 & 08 \\
\hline Pallor & 01 & 02 \\
\hline Hepatosplenomegaly & 00 & 01 \\
\hline Impaired conciousness & 00 & 01 \\
\hline Convulsions / Seizures & 00 & 01 \\
\hline Mortality & & \\
\hline
\end{tabular}


Table 2

Comparison of means of baseline laboratory investigations in Plasmodium vivax and Plasmodium falciparum infected patients on the first day of admission

\begin{tabular}{|c|c|c|c|c|c|}
\hline \multirow[t]{2}{*}{ Investigations } & \multicolumn{2}{|c|}{ Mean (SD) } & \multirow{2}{*}{$\begin{array}{l}\text { Mean Difference }(95 \% \\
\text { CI) }\end{array}$} & \multirow[t]{2}{*}{ T-Score } & \multirow[t]{2}{*}{ P value } \\
\hline & $\begin{array}{c}\text { P. falciparum (n } \\
=14)\end{array}$ & $\begin{array}{l}\text { P. vivax } \\
(n=18)\end{array}$ & & & \\
\hline CRP (mg/ l) & $29.4(10.9)$ & $14.5(3.7)$ & $14.9(6.7,23.2)$ & 3.8 & .002 \\
\hline$\%$ Parasitemia & $2.3(1.6)$ & $1.0(0.6)$ & $1.3(0.1,2.6)$ & 2.3 & .034 \\
\hline $\begin{array}{l}\text { Platelet count } \\
\text { (lac/cumm) }\end{array}$ & $0.7(0.2)$ & $1.3(0.3)$ & $0.6(0.3,0.9)$ & 3.9 & .001 \\
\hline $\begin{array}{l}\text { Total Bilirubin } \\
\text { (mg\%) }\end{array}$ & $4.2(2.2)$ & $1.3(0.3)$ & $2.9(1.4,4.5)$ & 3.9 & .001 \\
\hline ALT (U/L) & $95.9(95.8)$ & $29.6(10.9)$ & $66.2(2.1,134.5)$ & 2.1 & .057 \\
\hline AST (U/L) & $127.0(143.0)$ & $37.0(13.3)$ & $89.9(11.6,191.6)$ & 1.9 & .078 \\
\hline
\end{tabular}

Table 3

Correlation coefficients between mean CRP and various haematological and biochemical parameters in P.

Falciparum \& P. Vivax

\begin{tabular}{|c|c|c|c|c|}
\hline & \multicolumn{2}{|c|}{ P. Falciparum } & \multicolumn{2}{c|}{ P. Vivax } \\
\cline { 2 - 5 } & Correlation with CRP & P value & Correlation with CRP & P value \\
\hline \% Parasitemia & 0.90 & .000 & 0.32 & .204 \\
\hline Platelet count & -0.46 & .095 & 0.15 & .555 \\
\hline Total bilirubin & 0.65 & .011 & 0.15 & .542 \\
\hline ALT & 0.88 & .000 & -0.06 & .819 \\
\hline AST & 0.89 & .000 & -0.26 & .297 \\
\hline
\end{tabular}

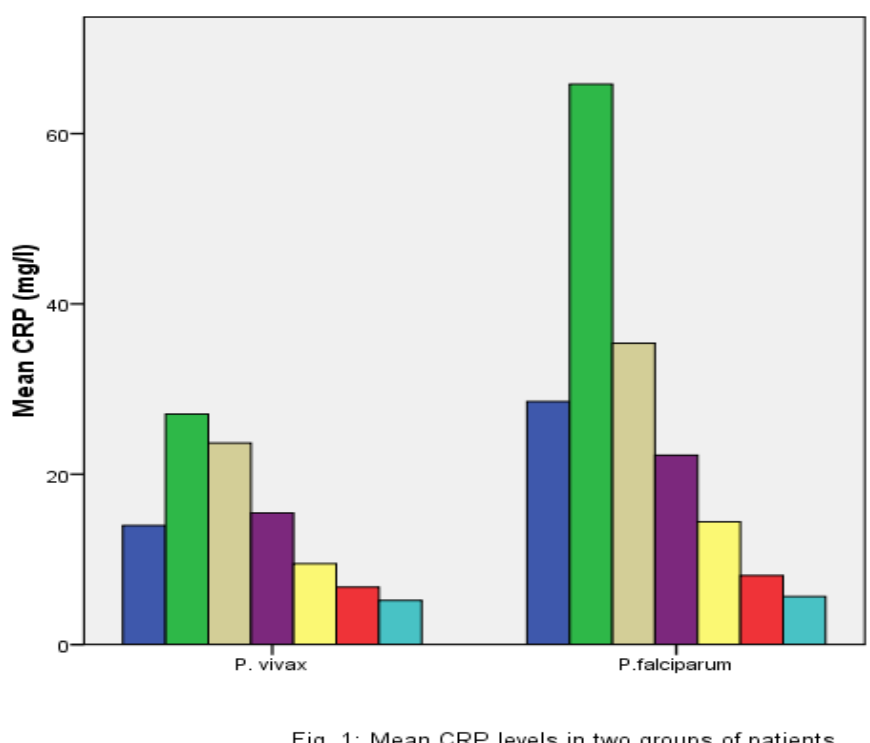

IV. Discussion

Malaria ia a complex multisystem disorder involving several mediators . CRP is one of the most widely used acute phase inflammatory proteins because of its early rise and rapid kinetics . It binds damaged host cells including erythrocytes infected by P. Falciparum resulting in their clearance by both humoral and cellular immune mechanisms [7].

The results obtained from this study showed that serum CRP concentrations are highly elevated in malaria patients. These findings are in agreement with previous studies which have also reported elevated levels of CRP in malaria patients $[3,8]$. However in our study mean CRP levels were found to be higher in the plasma 
of P. Falciparum infected patients compared to P.vivax infected patients . Previous studies have shown conflicting results as regards to this finding. While similar results were observed in a study from New Papua Guinea[9]. Other studies have reported either a higher serum CRP concentration in P.vivax patients [10] or no statistically significant difference between the two groups [11].

Our study involved sequential measurements of serum CRP concentrations in Malaria patients over a period of seven days . Highest values of mean CRP were found on the second day of treatment ; this finding is consistent with the fact that increase in parasitemia occurs upto $18 \mathrm{hrs}$ after initiation of antimalarial chemotherapy. The study showed significant correlation between serum CRP concentrations and various laboratory markers of severity of malaria like percentage parasitemia, serum bilirubin, serum concentrations of SGPT and SGOT in P.falciparum patients but not in P. Vivax. As certain current methods for assessing the therapeutic response to antimalarial drugs are imprecise [12] and since measurement of parasitemia may be confounded by inter observer variation, new markers are needed in malaria.Though some novel markers like TNF and interleukins have also been shown to correlate well with disease severity [13] but in a developing country like India where cost effectiveness of the test is a major concern, these markers may not be feasible. Hence measurement of serum CRP concentrations can provide a simple measurement of disease severity and efficacy of therapy especially in P. Falciparum infection where objective of treatment is early initiation of therapy and prevention of complications.

\section{Conclusion}

To conclude there seems to be a significant increase in serum CRP levels in malaria patients as shown in the present work.Serum CRP levels can provide an effective measure of disease severity and efficacy of therapy.

\section{References}

[1]. Malaria: Disease Burden in SEA Region. WHO publication; 2011[Updated 2011 Jan 18; Cited 2011 Sept 6]. WHO Regional Office for South-East Asia; [about 2 screens].

[2]. Sachs J, Malaney P (2002) The economic and social burden of malaria. Nature 415(6872): 680-5

[3]. Gillespie SH, Dow C, Raynes JG, Behrens RH, Chiodini PL, McAdam KP. Measurement of acute phase proteins for assessing severity of Plasmodium falciparum malaria. J Clin Pathol 1991;44:228-31.

[4]. McGuire W, D'Alessandro U, Olaleye BO, Thomson MC, Langerock P, Greenwood BM, Kwiatkowski D 1996. C-reactive protein and haptoglobin in the evaluation of a community-based malaria control programme. Trans R Soc Trop Med Hyg 90: 10-14.

[5]. Conroy AL, Liles WC, Molyneux ME, Rogerson SJ, Kain KC 2011. Performance characteristics of combinations of host biomarkers to identify women with occult placental malaria: a case-control study from Malawi. PLoS ONE 6: e28540.

[6]. Harpaz R, Edelman R, Wasserman SS, Levine MM, Davis JR, Sztein MB 1992. Serum cytokine profiles in experimental human malaria. Relationship to protection and disease course after challenge. J Clin Invest 90: 515-523.

[7]. Ansar ,W, Bandyopadhyay ,S.M, Chowdhury ,S, Habib ,S.H, Mandal, C. 2006. Role of C-reactive protein in complementmediated hemolysis in malaria. Glycoconj.J . 23: 233-240.

[8]. Hurt N, Smith T, Tanner M, Mwankusye S, Bordmann G, Weiss NA, et al. Evaluation of C-reactive protein and haptoglobin as malaria episode markers in an area of high transmission in Africa. Trans R Soc Trop Med Hyg 1994;88:182-6.

[9]. Manning L, Laman M, Law I, Bona C, Aipit S, et al. (2011) Features and Prognosis of Severe Malaria Caused by Plasmodium falciparum, Plasmodium vivax and Mixed Plasmodium Species in Papua New Guinean Children. PLoS ONE 6(12): e29203. doi:10.1371/journal.pone.0029203

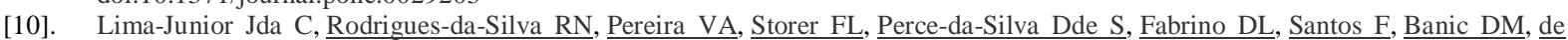
Oliveira-Ferreira J. Cells and mediators of inflammation (C-reactive protein, nitric oxide, platelets and neutrophils) in the acute and convalescent phases of uncomplicated Plasmodium vivax and Plasmodium falciparum infection. Mem Inst Oswaldo Cruz. 2012 Dec;107(8):1035-41

[11]. Paul R, Sinha PK, Bhattacharya R, Banerjee AK, Raychaudhuri P, Mondal J. Study of C reactive protein as a prognostic marker in malaria from Eastern India. Adv Biomed Res 2012;1:41

[12]. White NJ, Krishna S. Treatment of malaria: some considerations and limitations of the current methods of assessment. Trans R Soc Med Hyg 1989;83:767-77.

[13]. Andrade BB, Reis-Filho A, Souza-Neto SM, Clarencio J, Camargo LM, Barral A, Barral-Netto M 2010. Severe Plasmodium vivax malaria exhibits marked inflammatory imbalance. Malar J 9: 13. 